\title{
Should cashew and pistachio be clinically considered as one allergen?
}

Enrica Manca ${ }^{1}$, Nidhal Touati ${ }^{1}$, Maria De Filippo ${ }^{1}$, Elena Carboni ${ }^{1}$, Lucia Diaferio $^{1}$, Pascal Demoly $^{1}$, and Davide Caimmi ${ }^{1}$

${ }^{1}$ University Hospital Centre Montpellier

October 20, 2020

Should cashew and pistachio be clinically considered as one allergen?

Authors (Last Name and First Name): Manca Enrica ${ }^{1,2}$, Touati Nidhal ${ }^{1}$, De Filippo Maria ${ }^{1,3}$, Carboni Elena $^{1,4}$, Diaferio Lucia ${ }^{1,5}$, Demoly Pascal ${ }^{1,6}$, Caimmi Davide ${ }^{1,6}$

Affiliations :

1. Allergy Unit of the Department of Respiratory Diseases, University Hospital of Montpellier, France.

2. Pediatric Unit, University Hospital of Foggia, Italy.

3. Pediatric Unit, Fondazione IRCCS Policlinico San Matteo, University of Pavia, Italy.

4. Pediatric Unit, Ospedale Maggiore, ASST Cremona, Italy.

5. Department of Pediatrics, Giovanni XXIII Hospital, Aldo Moro University of Bari, Bari, Italy.

6. UMR-S 1136 INSERM-Sorbonne Université, Equipe EPAR - IPLESP, Paris, France.

Running title: Allergy to cashew and pistachio

Corresponding author:

Davide Caimmi, MD, $\mathrm{PhD}$

Allergy Unit, Département de Pneumologie et Addictologie

Hôpital Arnaud de Villeneuve, CHU de Montpellier, Univ Montpellier, France

371, Avenue du Doyen Gaston Giraud - 34090 Montpellier (France)

Phone number +33630061134

Email address:davide.caimmi@gmail.com

Word count: 1191

Number of tables: 2

This research did not receive any funding.

The Authors declare no conflict of interest for the present paper.

Keywords : cashew nut, food allergy, oral food challenge, pistachio, predictive values.

To the Editor, 
The prevalence of food allergy has increased over the last decade, affecting 1-3\% of the general population and $6-8 \%$ of children ${ }^{1}$. Tree nuts are the cause of $18-40 \%$ of food-induced anaphylaxis events and of more than $25 \%$ of food allergy related deaths ${ }^{2}$. Thus, the fear for a life-threatening allergic reaction after accidental exposure to an allergen has a significant impact on the quality of life of both patients and their families ${ }^{1,3}$. Among tree nuts, the prevalence of cashew allergy is increasing, being reported to cause even more severe anaphylactic reactions than peanut allergy ${ }^{1,4}$.

Cashew $(\mathrm{CN})$ and pistachio share a phylogenetic origin and are members of the Anacardiaceae family. Both serological and clinical cross-reactivity have been observed and may be explained by a high degree of homology of their seed storage proteins Ana o 1/Pis v 3 (7S vicilin; 78\%), Ana o 2/Pis v 2 (11S legumin; 80\%), and Ana o $3 /$ Pis v 1 (2S albumin; $70 \%)^{5,6}$. For these reasons, some authors refer to patients suffering from allergy to these nuts as presenting with the cashew/pistachio syndrome ${ }^{8}$.In children with CN sensitization, an elimination diet is prescribed for both foods, although oral food challenges (OFC) are essential to confirm or exclude allergy to both ${ }^{6}$.

Through a retrospective chart review, we aimed to assess the safety of reintroduction of one of these two nuts at home based on negative allergy testing for the other one. Our secondary objective was to determine the concordance and predictive values of skin prick tests (SPT) with the prick by prick method for OFC outcomes.

We included all patients admitted to the Allergy Unit of the University Hospital of Montpellier, between January 2006 and March 2020, for suspected allergy to CN and/or pistachio, based on clinical history and/or positive SPT, who underwent open OFC for CN and/or pistachio. We defined as "allergic" those patients with a positive OFC, based on international guidelines for assessing OFC outcomes ${ }^{7}$. In each patient, we evaluated age, sex, comorbidities (asthma and atopic dermatitis), results of SPT (positive when wheal size was [?] $3 \mathrm{~mm}$ ), specific $\operatorname{IgE}$ and $\mathrm{OFC}$. Ana o $3 \mathrm{IgE}$ were considered positive when $>0,1 \mathrm{kUA} / \mathrm{L}$. The study was approved by a local ethic committee (IRB MPL202000401, Clinical Trial NCT04304586). Missing data were included in the determination of PPV and NPV and were considered MAR.

We included 115 patients, with a median age of 9 years (3 years-20 years); 65 of them were males (56.5\%). Eighty-seven patients (75.7\%) had positive SPT to CN, 99 (86.1\%) to pistachio and 77 to both (67.0\%). Cashew SPT data were missing for 3 patients, and pistachio SPT was missing for 3 additional patients. Of 24 patients with a negative SPT to CN, 20(83.3\%) had a positive SPT to pistachio. On the other hand, $9(69 \%)$ of the 13 patients with a negative SPT to pistachio had a positive SPT to CN. Based on our results, the Positive and Negative Predictive Value (PPV and NPV) of SPT to CN and pistachio are shown in Table 1.

Among the 115 patients who underwent an OFC, 37 were tested to both nuts, 41 only to cashew and37 only to pistachio (Table 2). OFC was positive for both nuts in 5 patients (4.3\%), who presented non-severe cutaneous reactions in 3 cases during both tests, whereas the other 2 presented anaphylactic reactions during both OFC.

Among our patients with a positive OFC to cashew (32), only 4 had negative IgE for Ana o 3. However, using a cut-off level of $2 \mathrm{kUA} / \mathrm{L}$, we found that Ana o 3 had a PPV of $64.3 \%(35.1-87.2 \%, 95 \% \mathrm{CI})$ for a positive CN OFC, considering 11 missing data of Ana o 3 level. Eleven patients (34.3\%) did not have a prior history of clinical reactivity to CN, $11(34.3 \%)$ reported a history of anaphylaxis, and $10(31.2 \%)$ reported non-severe cutaneous reactions.

Of the 46 patients with negative CN OFC, 22 underwent $\mathrm{OFC}$ to pistachio. All of them were negative. Among these patients, 20 (91\%) had positive pistachio SPT and IgE, $1(4.5 \%)$ had positive pistachio SPT but negative IgE and 1 (4.5\%) had negative both SPT and IgE. Of the other 24 patients who weren't challenged, 11 (45\%) had positive allergic workup (both SPT and IgE) to pistachio, $4(16.7 \%)$ had positive SPT only, $2(8.3 \%)$ had negative SPT but positive IgE and $5(20.8 \%)$ had negative SPT.

Among 19 patients (16.5\%) who had a positive pistachio OFC, 15 (78.9\%) had no reported history of allergic 
reaction to pistachio, $3(15.8 \%)$ had prior non-severe cutaneous reactions and $1(5.3 \%)$ reported a history of anaphylaxis (Table 2).

Among the fifty-six patients with a negative pistachio OFC, 11 (14.7\%) had a positive CN OFC and 22 had a negative CN OFC. Among these 22 patients, 17 (77\%) had positive CN SPT and IgE with Ana o 3 positive in $4(18.2 \%)$ patients and negative in $7(41 \%)$.

Moreover, 18 (94.7\%) of the 19 patients with a positive pistachio OFC had positive CN SPT, but only 5 of these had a positive CN OFC; on the contrary, 34 of the 56patients with negative pistachio OFC $(60.7 \%)$ had a positive CN SPT, and, among these, only 11(32\%) had a positive CN OFC.

Considering missing data, PPV and NPV of OFC are shown in Table1.

By presenting these data, we want to highlight the differences in both sensitization and allergy between CN and pistachio. As reported in the Improvement of Diagnostic mEthods for Allergy assessment (IDEAL) study, $98 \%$ of cashew-sensitized patients were co-sensitized to pistachio, and $\mathrm{CN}$ is often the primary sensitizer (the first nut the patient is sensitized to $)^{6}$. Compared to this study, our results demonstrated a lower rate of $67 \%$ cashew/pistachio co-sensitization.

In accordance with findings from prior publications, in our study, serum IgE to Ana o3 showed an excellent diagnostic accuracy, suggesting that Ana o3 may be used in clinical practice to predict the likelihood of clinical reactivity and outcomes of an OFC to cashew ${ }^{8,9}$. However, using a cut-off level of $2 \mathrm{kUA} / \mathrm{L}$ as described by Lange et al, only 9 of our 32 patients (28.1\%) allergic to $\mathrm{CN}$ would have correctly been identified without an OFC, whereas $12(37.5 \%)$ would have been incorrectly classified as tolerant. Nevertheless, the cut-off level was accurate in predicting tolerant patients, among which only 1 of $46(2.2 \%)$ had higher level of Ana o $3{ }^{9}$.Furthermore, our results did not demonstrate a statistically significant correlation between the severity of reaction and the levels of IgE to Ana o 3 .

In conclusion, we could say that it is safe to introduce pistachio at home if patients have a negative OFC to $\mathrm{CN}$, independently from its $\mathrm{SPT}$ and $\mathrm{IgE}$, and that when an OFC to pistachio is positive, the patient is highly likely to be allergic to $\mathrm{CN}$ as well. Nevertheless, the data we present come from a single center, are retrospective, and should be strengthen and possibly confirmed by a prospective analysis. Therefore, the safest conclusion, so far, is that $\mathrm{CN}$ and pistachio should be considered as two different sources of allergens and a complete allergy work-up for both, including OFC, should be performed, before authorizing a safe reintroduction at home.

Manca $\mathrm{E}^{1,2}$, Touati $\mathrm{N}^{1}$, De Filippo $\mathrm{M}^{1,3}$, Carboni $\mathrm{E}^{1,4}$, Diaferio $\mathrm{L}^{1,5}$, Demoly $\mathrm{P}^{1,6}$, Caimmi $\mathrm{D}^{1,6}$

1. Allergy Unit of the Department of Respiratory Diseases, University Hospital of Montpellier, France.

2. Pediatric Unit, University Hospital of Foggia, Italy.

3. Pediatric Unit, Fondazione IRCCS Policlinico San Matteo, University of Pavia, Italy.

4. Pediatric Unit, Ospedale Maggiore, ASST Cremona, Italy

5. Department of Pediatrics, Giovanni XXIII Hospital, Aldo Moro University of Bari, Bari, Italy.

6. UMR-S 1136 INSERM-Sorbonne Universite, Equipe EPAR - IPLESP, Paris, France.

\section{References}

1. Sanchiz A, Cuadrado C, Dieguez MC, Ballesteros I, Rodriguez J, Crespo JF, et al. Thermal processingeffects on the IgE-reactivity of cashew and pistachio. Food Chem 2018;245:595-602.

2. Bock SA, Munoz-Furlong A, Sampson HA. Further fatalities caused by anaphylactic reactions to food, 2001-2006. J AllergyClinImmunol 2007;119:1016-1018.

3. Smeekens J.M., Bagley K., KulisM. Tree Nut Allergies: Allergen Homology, Cross-Reactivity, and Implications for Therapy. Clin ExpAllergy 2018;48:762-772. 
4. Saba L, Clerc-Urmes I, Delahaye C, Chevillot E, Jarlot-Chevaux S, Dumond P, et al. Predictive factors of allergy to pistachio in children allergic to cashew nut. Pediatr Allergy Immunol 2020. Online ahead of print.

5. Bastiaan-Net S, Reitsma M, Cordewener JHG, Van der Valk JPM, America TAHP, Dubois AEJ, et al. IgE Cross-Reactivity of Cashew Nut Allergens. Int Arch Allergy Immunol 2019;178:19-32.

6. Van der Valk JPM, Bouche RE, Gerth van Wijk R, de Groot H, Wichers HJ, Dubois AEJ, et al. Low percentage of clinically relevant pistachio nut and mango co-sensitisation in cashew nut sensitised children. ClinTransl Allergy 2017;7:8.

7. Bindslev-Jensen C, Ballmer-Weber BK, Bengtsson U, Blanco C, Ebner C, Hourihane J, et al. Standardization of food challenges in patients with immediatereactions to foods - position paper from the European Academyof Allergology and Clinical Immunology. Allergy 2004;59:690-697.

8. Savvatianos S, Konstantinopoulos AP, Borga A, Stavroulakis G, LidholmJ, Borres MP et al. Sensitization to cashew nut $2 \mathrm{~S}$ albumin, Ana o 3, is highly predictive of cashew and pistachio allergy in Greek children. J Allergy Clin Immunol 2015;136:192-194.

9. Lange L, Lasota L, Finger A, Vlajnic D, Busing S, Meister J, et al. Ana o 3-specific IgE Is a Good Predictor for Clinically Relevant Cashew Allergy in Children. Allergy 2017;72:598-603.

10. Sampson HA, Munoz-Furlong A, Campbell RL, Adkinson NF Jr, Bock SA, Branum A, et al. Second symposium on the definition and management of anaphylaxis: summary report- Second National Institute of Allergy and Infectious Disease/Food Allergy and Anaphylaxis Network Symposium. J Allergy Clin Immunol 2006;117:391-397.

Table 1 - Predictive Values for SPT and OFC found in our study.

\begin{tabular}{lllll}
\hline & & Predictive values & $95 \%$ II $^{*}$ \\
\hline SPT & Positive for CN & PPV & $35.6 \%$ for CN allergy & $25.6-46.6 \%$ \\
& & $88.5 \%$ for positive SPT to pistachio & $79.9-94.3 \%$ \\
& Positive for pistachio & & $19.2 \%$ for pistachio allergy & $12.0-28.4 \%$ \\
& & $77.8 \%$ for positive SPT to CN & $68.3-87.5 \%$ \\
& Negative for CN & NPV & $16 \%$ for negative SPT to pistachio & $4.6-35.9 \%$ \\
& Negative for pistachio & & $30.8 \%$ for negative SPT to CN & $9.1-61.4 \%$ \\
OFC & Positive for CN & PPV & $15.6 \%$ for a positive OFC to pistachio & $5.3-32.8 \%$ \\
& Positive for pistachio & & $26.3 \%$ for a positive OFC to CN & $9.1-51.2 \%$ \\
& Negative for CN & NPV & $47.8 \%$ for a negative OFC to pistachio & $32.9-63 \%$ \\
& Negative for pistachio & & $19.6 \%$ for a negative OFC to CN & $26.5-53.2 \%$ \\
\hline
\end{tabular}

Legend - SPT: Skin Prick Tests; OFC: Oral Food Challenge; PPV: Positive Predictive Value; NPV: Negative Predictive Value; CN: Cashew Nut; CI: Confidence Interval; Positive SPT: wheal size $>3 \mathrm{~mm}$.

* Exact method

Table 2 - Clinical characteristics of patients undergoing OFC to pistachio and cashew. 


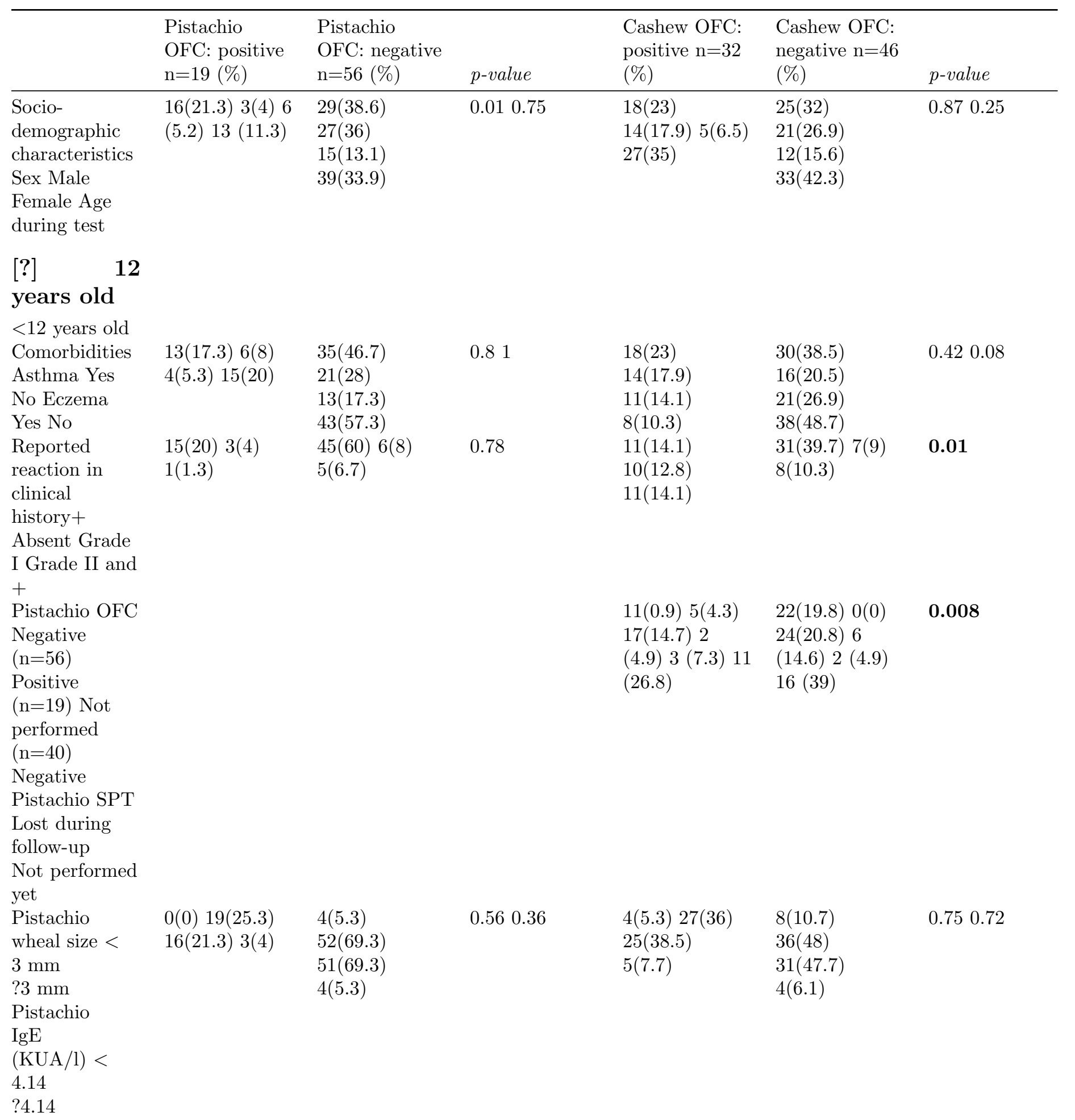




\begin{tabular}{|c|c|c|c|c|c|c|}
\hline & $\begin{array}{l}\text { Pistachio } \\
\text { OFC: positive } \\
\mathrm{n}=19(\%)\end{array}$ & $\begin{array}{l}\text { Pistachio } \\
\text { OFC: negative } \\
\mathrm{n}=56(\%)\end{array}$ & p-value & $\begin{array}{l}\text { Cashew OFC: } \\
\text { positive } \mathrm{n}=32 \\
(\%)\end{array}$ & $\begin{array}{l}\text { Cashew OFC: } \\
\text { negative } \mathrm{n}=46 \\
(\%)\end{array}$ & p-value \\
\hline $\begin{array}{l}\text { Cashew OFC } \\
\text { Negative } \\
(\mathrm{n}=46) \\
\text { Positive } \\
(\mathrm{n}=32) \text { Not } \\
\text { performed } \\
(\mathrm{n}=37) \\
\text { Negative CN } \\
\text { SPT } \\
\text { Lost during } \\
\text { follow-up } \\
\text { Not performed } \\
\text { yet }\end{array}$ & $\begin{array}{l}0(0) 5(6.7) \\
14(18.7) 1 \\
(2.7) 3(8.1) 10 \\
(27)\end{array}$ & $\begin{array}{l}22(29.3) \\
11(14.7) \\
23(30.7) 16 \\
(62.2) 2(5.4) 5 \\
(13.5)\end{array}$ & 0.008 & & & \\
\hline $\begin{array}{l}\text { Cashew } \\
\text { wheal size }< \\
3 \mathrm{~mm} \\
? 3 \mathrm{~mm} \\
\text { Cashew IgE } \\
(\mathrm{KUA} / \mathrm{l})< \\
1.125 \\
? 1.125 \text { Ana } \\
\text { o } 3 \mathrm{IgE} \\
(\mathrm{KUA} / \mathrm{l})< \\
2 \\
? 2\end{array}$ & $\begin{array}{l}1(1.3) \\
18(24.3) \\
10(15.9) \\
9(14.3) \\
4(11.1) \\
6(16.7)\end{array}$ & $\begin{array}{l}20(27) \\
33(44.6) \\
31(49.2) \\
13(20.6) \\
24(66.7) \\
2(5.6)\end{array}$ & $\begin{array}{l}\mathbf{0 . 0 8} 0.25 \\
\mathbf{0 . 0 0 2}\end{array}$ & $\begin{array}{l}0(0) 31(40.3) \\
15(20.2) \\
14(18.9) \\
12(24) 9(18)\end{array}$ & $\begin{array}{l}8(10.4) \\
38(49.3) \\
29(39.1) \\
16(21.6) \\
28(56) 1(2)\end{array}$ & $\begin{array}{l}\mathbf{0 . 0 2} 0.27 \\
<\mathbf{0 . 0 0 1}\end{array}$ \\
\hline $\begin{array}{l}\text { Cut-off for } \\
\text { specific IgE } \\
\text { levels are } \\
\text { based on the } \\
\text { articles by }\end{array}$ & $\begin{array}{l}\text { Cut-off for } \\
\text { specific IgE } \\
\text { levels are } \\
\text { based on the } \\
\text { articles by }\end{array}$ & $\begin{array}{l}\text { Cut-off for } \\
\text { specific IgE } \\
\text { levels are } \\
\text { based on the } \\
\text { articles by }\end{array}$ & $\begin{array}{l}\text { Cut-off for } \\
\text { specific IgE } \\
\text { levels are } \\
\text { based on the } \\
\text { articles by }\end{array}$ & $\begin{array}{l}\text { Cut-off for } \\
\text { specific IgE } \\
\text { levels are } \\
\text { based on the } \\
\text { articles by }\end{array}$ & $\begin{array}{l}\text { Cut-off for } \\
\text { specific IgE } \\
\text { levels are } \\
\text { based on the } \\
\text { articles by }\end{array}$ & $\begin{array}{l}\text { Cut-off for } \\
\text { specific IgE } \\
\text { levels are } \\
\text { based on the } \\
\text { articles by }\end{array}$ \\
\hline $\begin{array}{l}\text { Lange et al. } \\
\text { and }\end{array}$ & $\begin{array}{l}\text { Lange et al. } \\
\text { and }\end{array}$ & $\begin{array}{l}\text { Lange et al. } \\
\text { and }\end{array}$ & $\begin{array}{l}\text { Lange et al. } \\
\text { and }\end{array}$ & $\begin{array}{l}\text { Lange et al. } \\
\text { and }\end{array}$ & $\begin{array}{l}\text { Lange et al. } \\
\text { and }\end{array}$ & $\begin{array}{l}\text { Lange et al. } \\
\text { and }\end{array}$ \\
\hline $\begin{array}{l}\text { Cetinkaya t } \\
\text { al. }[4,9] \text {. } \\
\text { + Grading of } \\
\text { anaphylaxis } \\
\text { based on the } \\
\text { article by }\end{array}$ & $\begin{array}{l}\text { Cetinkaya t } \\
\text { al. }[4,9] \text {. } \\
+ \text { Grading of } \\
\text { anaphylaxis } \\
\text { based on the } \\
\text { article by }\end{array}$ & $\begin{array}{l}\text { Cetinkaya t } \\
\text { al. }[4,9] \text {. } \\
\text { + Grading of } \\
\text { anaphylaxis } \\
\text { based on the } \\
\text { article by }\end{array}$ & $\begin{array}{l}\text { Cetinkaya t } \\
\text { al. }[4,9] \text {. } \\
+ \text { Grading of } \\
\text { anaphylaxis } \\
\text { based on the } \\
\text { article by }\end{array}$ & $\begin{array}{l}\text { Cetinkaya t } \\
\text { al. }[4,9] \text {. } \\
+ \text { Grading of } \\
\text { anaphylaxis } \\
\text { based on the } \\
\text { article by }\end{array}$ & $\begin{array}{l}\text { Cetinkaya t } \\
\text { al. }[4,9] \text {. } \\
\text { + Grading of } \\
\text { anaphylaxis } \\
\text { based on the } \\
\text { article by }\end{array}$ & $\begin{array}{l}\text { Cetinkaya t } \\
\text { al. }[4,9] \text {. } \\
+ \text { Grading of } \\
\text { anaphylaxis } \\
\text { based on the } \\
\text { article by }\end{array}$ \\
\hline $\begin{array}{l}\text { Sampson et } \\
\text { al [10] }\end{array}$ & $\begin{array}{l}\text { Sampson et } \\
\text { al [10] }\end{array}$ & $\begin{array}{l}\text { Sampson et } \\
\text { al [10] }\end{array}$ & $\begin{array}{l}\text { Sampson et } \\
\text { al [10] }\end{array}$ & $\begin{array}{l}\text { Sampson et } \\
\text { al [10] }\end{array}$ & $\begin{array}{l}\text { Sampson et } \\
\text { al [10] }\end{array}$ & $\begin{array}{l}\text { Sampson et } \\
\text { al }[10]\end{array}$ \\
\hline
\end{tabular}

Legend - OFC: Oral Food Challenge. 